International Journal of Signal System Control and Engineering Application 3 (1): 1-6, 2010

ISSN: 1997-5422

(C) Medwell Journals, 2010

\title{
Estimation and Optimal Control with Reduced Order Observers via Orthogonal Functions
}

\author{
B.M. Mohan and Sanjeeb Kumar Kar \\ Department of Electrical Engineering, Indian Institute of Technology, Kharagpur-721302, India
}

\begin{abstract}
Using Block-Pulse Functions (BPFs) and Shifted Legendre Polynomials (SLPs) 2 recursive algorithms are presented for the analysis of linear time-invariant optimal control systems using reduced order observers. An illustrative example is included to demonstrate the superiority of proposed recursive algorithms over the existing recursive/nonrecursive approaches.
\end{abstract}

Key words: Optimal control, observer, orthogonal functions, block-pulse functions, shifted legendre polynomials

\section{INTRODUCTION}

State feedback control system design requires the knowledge of the state vector of the controlled plant. Sometimes, no state variables or only a few state variables are available for measurement. In such cases an observer (Luenberger, 1964) is incorporated to estimate the unknown plant state variables if the plant is observable. This problem is stated as follows:

Consider a linear time-invariant completely observable and completely controllable system described by:

$$
\begin{gathered}
\dot{x}(t)=\mathrm{Ax}(\mathrm{t})+\mathrm{Bu}(\mathrm{t}) \\
\mathrm{y}(\mathrm{t})=\mathrm{Cx}(\mathrm{t})
\end{gathered}
$$

Where $\mathrm{u}(\mathrm{t}), \mathrm{x}(\mathrm{t})$ and $\mathrm{y}(\mathrm{t})$ are the plant input, state and output vectors, respectively and $A, B$ and $C$ are $n \times n$; $\mathrm{n} \times \mathrm{r}$ and $\mathrm{p} \times \mathrm{n}$ real, constant matrices, respectively. Assume that rank of $\mathrm{C}$ is $\mathrm{p}$. An observer described by:

$$
\begin{gathered}
\dot{z}(t)=F z(t)+G u(t)+H y(t) \\
\hat{x}(t)=L_{1} y(t)+L_{2} z(t)
\end{gathered}
$$

can provide the estimate $\hat{x}(t)$ for the state $x(t)$ where $F, G$, $H, L_{1}$ and $L_{2}$ are real constant $q \times q, q \times r, q \times p, n \times p$ and $n \times q$ matrices, respectively and $\mathrm{q}=\mathrm{n}-\mathrm{p}$ when the following conditions are satisfied (Bongiorno and Youla, 1968):

$$
\mathrm{G}=\Gamma \mathrm{B}
$$

Where, $\Gamma$ is the $\mathrm{q}^{\times \mathrm{n}}$ matrix which is the solution of the matrix equation:

$$
\begin{gathered}
\Gamma A-F \Gamma=H C \\
z(t)=\Gamma x(t)+e(t) \\
\dot{e}(t)=F e(t) \\
L_{1} C+L_{2} \Gamma=I_{n}
\end{gathered}
$$

When an observer is incorporated to generate an estimate $\hat{x}(t)$ of the plant state vector we need to choose the matrix $\mathrm{K}$ in the feedback law:

$$
u(t)=-K \hat{x}(t)
$$

so that the cost function:

$$
J=\frac{1}{2} \int_{t_{0}}^{\infty}\left[x^{T}(t) Q x(t)+u^{T}(t) R u(t)\right] d t
$$

is a minimum. The $\mathrm{n} \times \mathrm{n}$ matrix $\mathrm{Q}$ and the $\mathrm{r} \times \mathrm{r}$ matrix $\mathrm{R}$ are real symmetric positive semidefinite and real symmetric positive definite, respectively. Substituting Eq. 2, 4, 7 and 9 into Eq. 10, we obtain:

$$
\mathrm{u}^{*}(\mathrm{t})=-\mathrm{K}\left[\mathrm{x}(\mathrm{t})+\mathrm{L}_{2} \mathrm{e}(\mathrm{t})\right]
$$

Inserting Eq. 12 into Eq. 1 yields:

Corresponding Author: Sanjeeb Kumar Kar, Department of Electrical Engineering, Indian Institute of Technology, Kharagpur-721302, India 


$$
\dot{x}(t)=\tilde{A} x(t)+\tilde{B} e(t)
$$

Where:

$$
\tilde{\mathrm{A}}=\mathrm{A}-\mathrm{BK}
$$

and

$$
\tilde{\mathrm{B}}=-\mathrm{BKL}_{2}
$$

It follows from Eq. 12 that the solutions of Eq. 8 and 13 are necessary to compute the control law $\mathrm{u}^{*}(\mathrm{t})$. In the last three and half decades, orthogonal functions approach (Rao, 1983; Jiang and Schaufelberger, 1992; Datta and Mohan, 1995) was successfully applied to study varieties of problems in systems and control. It became quite popular numerically and computationally as it converts calculus (differential or integral) into algebra in the sense of least squares i.e., dynamical equations of a system can be converted into a set of algebraic equations whose solution simply leads to the solution of dynamical equations.

The problem of optimal control incorporating reduced order observers has been successfully studied via different classes of orthogonal functions, namely blockpulse functions (Kawaji, 1983) shifted legendre polynomials (Chou and Horng, 1985b) and (Yang and Chen, 1988) shifted Jacobi polynomials (Lee et al., 1986), general orthogonal polynomials (Chang and Lee, 1986), Fourier series (Chung and Sun, 1987; Yang and Chen, 1988), associated legendre polynomials (Yang and Chen, 1988), Chebyshev polynomials of first kind and singleterm walsh series (Palanisamy and Raghunathan, 1989). The approach followed is non resursive while it is recursive (Kawaji, 1983; Palanisamy and Raghunathan, 1989) making the approach by Chou and Horng (1985a, b), Lee et al. (1986), Chang and Lee (1986), Chung and Sun (1987) and Yang and Chen (1988) computationally not attractive. Application of orthogonal functions has been extended to 2 more closely related problems in this decade. That is costate estimation (Fahroo and Ross, 2001) and fault detection using state observers (De Melo and Morais, 2007) have been studied via orthogonal functions. The basic idea of this continued research activity is to develop computationally efficient algorithms. In this study, using BPFs and SLPs 2 recursive algorithms are developed for solving the problem of linear optimal control systems incorporating reduced order observers.

Orthogonal functions and their properties: Here, we consider 2 classes of orthogonal functions, namely BPFs and SLPs and discuss their properties.

Block-pulse functions: A set of $\mathrm{m}$ block-pulse functions (Fahroo and Ross, 2001; Jiang and Schaufelberger, 1992) orthogonal over $\mathrm{t} \in\left[\mathrm{t}_{0}, \mathrm{t}\right]$ is defined as:

$$
\phi_{\mathrm{i}}(\mathrm{t})=\left\{1, \mathrm{t}_{0}+\mathrm{iT} \leq \mathrm{t}<\mathrm{t}_{0}+(\mathrm{i}+1) \mathrm{T} 0, \text { otherwise }\right\}
$$

for $\mathrm{i}=0,1,2, \ldots \mathrm{m}-1$ and

$$
\mathrm{T}=\frac{\mathrm{t}_{\mathrm{f}}-\mathrm{t}_{0}}{\mathrm{~m}} \text {, the block }- \text { pulses width }
$$

A square integrable function $\mathrm{f}(\mathrm{t})$ on $\mathrm{t}_{0} \leq t \leq \mathrm{t}_{\mathrm{f}}$ can be approximately represented in terms of $\mathrm{BPF}$ as:

$$
f(t) \approx \sum_{i=0}^{m-1} f_{i} \phi_{i}(t)=f^{T} \phi(t)
$$

Where:

$$
\mathrm{f}=\left[\mathrm{f}_{0}, \mathrm{f}_{1}, \ldots, \mathrm{f}_{\mathrm{m}-1}\right]^{\mathrm{T}}
$$

is a m-dimensional block-pulse spectrum of $\mathrm{f}(\mathrm{t})$ and

$$
\phi(t)=\left[\phi_{0}(t), \phi_{1}(t), \ldots, \phi_{m^{\prime}-1}(t)\right]^{T}
$$

a m-dimensional BPF vector. $\mathrm{f}_{\mathrm{i}}$ in Eq. 18 is given by:

$$
f_{i}=\frac{1}{T} \int_{t_{0}+i T}^{t_{0}+(i+1) T} f(t) d t
$$

which is the average value of $f(t)$ over $t_{0}+i T \leq t \leq t_{0}+(i+1) T$. Integrating $\phi(t)$ once with respect to $t$ and expressing the result in $\mathrm{m}$-set of $\mathrm{BPF}$, we have:

$$
\int_{t_{0}}^{t} \phi(\tau) d \tau \approx P \phi(t)
$$

Where:

$$
\mathrm{P}=\mathrm{T}\left[\begin{array}{ccccc}
\frac{1}{2} & 1 & 1 & \cdots & 1 \\
0 & \frac{1}{2} & 1 & \cdots & 1 \\
0 & 0 & \frac{1}{2} & \cdots & 1 \\
\vdots & \vdots & \vdots & & \vdots \\
0 & 0 & 0 & \cdots & \frac{1}{2}
\end{array}\right]
$$

is called the integration operational matrix of $\mathrm{BPF}$ and it is a $m \times m$ upper triangular matrix. Matrix $P$ will be helpful in deriving a recursive algorithm.

Shifted legendre polynomials: A set of SLP (Datta and Mohan, 1995), denoted by $\left\{\phi_{i}(t)\right\}$ for $i=0,1,2, \ldots, m-1$ is orthogonal with respect to the weighting function $\mathrm{w}(\mathrm{t})=1$ over the interval $\left[\mathrm{t}_{0}, \mathrm{t}_{\mathrm{f}}\right]$. These polynomials satisfy the recurrence relation:

$$
\phi_{i+1}(t)=\frac{(2 i+1)}{(i+1)} \varphi \phi_{i}(t)-\frac{i}{(i+1)} \phi_{i-1}(t)
$$

for $i=1,2,3, \ldots \ldots$ 


$$
\begin{gathered}
\varphi=\frac{2\left(t-t_{0}\right)}{\left(t_{f}-t_{0}\right)}-1 \\
\phi_{0}(t)=1 \text { and } \phi_{1}(t)=\varphi
\end{gathered}
$$

A function $\mathrm{f}(\mathrm{t})$ that is square integrable on $\mathrm{t} \in\left[\mathrm{t}_{0}, \mathrm{t}_{\mathrm{f}}\right]$ can be represented in terms of SLP as shown in Eq. 18 . Here, $\mathrm{f}$ is called legendre spectrum of $\mathrm{f}(\mathrm{t})$ and $\phi(\mathrm{t})$ is called SLP vector. $\mathrm{f}_{\mathrm{i}}$ in Eq. 18 is given by:

$$
f_{i}=\frac{(2 i+1)}{\left(t_{f}+t_{0}\right)} \int_{t_{0}}^{t_{f}} f(t) \phi_{i}(t) d t
$$

SLP satisfy the relation:

$$
\phi_{i}(t)=\frac{\left(t_{f}-t_{0}\right)}{2(2 i+1)}\left(\frac{d}{d t} \phi_{i+1}(t)-\frac{d}{d t} \phi_{i-1}(t)\right)
$$

for $i=1,2,3, \ldots \ldots$.

Integrating $\phi_{0}(\mathrm{t})$ once with respect to $\mathrm{t}$ and expressing the result in terms of SLP, we have:

$$
\int_{t_{0}}^{t} \phi_{0}(\tau) d \tau=\frac{\left(t_{f}-t_{0}\right)}{2}\left[\phi_{0}(t)+\phi_{1}(t)\right]
$$

Integrating Eq. 28 once with respect to t, we obtain:

$$
\int_{t_{0}}^{t} \phi_{i}(\tau) d \tau=\frac{\left(t_{f}-t_{0}\right)}{2(2 i+1)}\left[\phi_{i+1}(t)-\phi_{i-1}(t)\right]
$$

Equation 29 and 30 can be written in the form of Eq. 22 where;

$$
\mathrm{P}=\frac{\left(\mathrm{t}_{\mathrm{f}}-\mathrm{t}_{0}\right)}{2}\left[\begin{array}{ccccccc}
1 & 1 & 0 & 0 & \cdots & 0 & 0 \\
\frac{-1}{3} & 0 & \frac{1}{3} & 0 & \cdots & 0 & 0 \\
0 & \frac{-1}{5} & 0 & \frac{1}{5} & \cdots & 0 & 0 \\
\vdots & \vdots & \vdots & \vdots & & \vdots & \vdots \\
0 & 0 & 0 & 0 & \cdots & 0 & \frac{1}{2 \mathrm{~m}-3} \\
0 & 0 & 0 & 0 & \cdots & \frac{-1}{2 \mathrm{~m}-1} & 0
\end{array}\right]
$$

which is called the integration operational matrix of SLP. As can be seen from Eq. 31, it is a tridiagonal matrix of order $m \times m$ and it plays an important role in deriving a recursive algorithm.

Analysis of linear optimal control systems incorporating observers: We express the state vector $\dot{x}(t)$ and the error vector $\mathrm{e}(\mathrm{t})$ in terms of orthogonal functions as:

$$
\mathrm{x}(\mathrm{t}) \approx \sum_{\mathrm{i}=0}^{\mathrm{m}-1} \mathrm{x}_{\mathrm{i}} \phi_{\mathrm{i}}(\mathrm{t})=\mathrm{X} \phi(\mathrm{t})
$$

and

$$
\mathrm{e}(\mathrm{t}) \approx \sum_{\mathrm{i}=0}^{\mathrm{m}-1} \mathrm{e}_{\mathrm{i}} \phi_{\mathrm{i}}(\mathrm{t})=\mathrm{E} \phi(\mathrm{t})
$$

Where:

and

$$
\mathrm{X}=\left[\mathrm{x}_{0}, \mathrm{x}_{1}, \ldots, \mathrm{x}_{\mathrm{m}-1}\right]
$$

$$
\mathrm{E}=\left[\mathrm{e}_{0}, \mathrm{e}_{1}, \ldots, \mathrm{e}_{\mathrm{m}-1}\right]
$$

Which are not yet known and $\phi(t)$ is either $B P F$ vector $\mathrm{B}(\mathrm{t})$ or SLP vector $\mathrm{L}(\mathrm{t})$. Integrating Eq. 8 once with respect to t and using Eq. 22 and 33 yield:

Where:

$$
\mathrm{E}=\mathrm{E}_{0}+\mathrm{FEP}
$$

$$
\begin{aligned}
\mathrm{E}_{0} & =\left[\mathrm{e}\left(\mathrm{t}_{0}\right), \mathrm{e}\left(\mathrm{t}_{0}\right), \ldots, \mathrm{e}\left(\mathrm{t}_{0}\right)\right] \text { if } \phi(\mathrm{t})=\mathrm{B}(\mathrm{t}) \\
& =\left[\mathrm{e}\left(\mathrm{t}_{0}\right), 0, \ldots, 0\right] \quad \text { if } \phi(\mathrm{t})=\mathrm{L}(\mathrm{t})
\end{aligned}
$$

Similarly, from Eq. 13, 22 and 32 we obtain:

$$
\mathrm{X}=\mathrm{X}_{0}+(\tilde{\mathrm{AX}}+\tilde{\mathrm{B}} \mathrm{E}) \mathrm{P}
$$

Where:

$$
\begin{aligned}
\mathrm{X}_{0} & =\left[\mathrm{x}\left(\mathrm{t}_{0}\right), \mathrm{x}\left(\mathrm{t}_{0}\right), \ldots, \mathrm{x}\left(\mathrm{t}_{0}\right)\right] \text { if } \phi(\mathrm{t})=\mathrm{B}(\mathrm{t}) \\
& =\left[\mathrm{x}\left(\mathrm{t}_{0}\right), 0, \ldots, 0\right] \quad \text { if } \phi(\mathrm{t})=\mathrm{L}(\mathrm{t})
\end{aligned}
$$

Algebraic Eq. 36 and 39 are to be solved for the unknowns $\mathrm{E}$ and $\mathrm{X}$. Once $\mathrm{E}$ and $\mathrm{X}$ are available, the desired control law $\mathrm{u}^{*}(\mathrm{t})$ can be computed from Eq. 12 as:

$$
\mathrm{u}^{*}(\mathrm{t})=-\mathrm{K}\left[\mathrm{X}+\mathrm{L}_{2} \mathrm{E}\right] \phi(\mathrm{t})
$$

Kronecker product method: Equation 36 and 39 can be written as:

$$
\operatorname{Vec}(E)=\left(I_{q m}-P^{T} \otimes F\right)^{-1} \operatorname{Vec}\left(E_{0}\right)
$$

and:

$$
\operatorname{Vec}(X)=\left(I_{n m}-P^{T} \otimes \tilde{A}\right)^{-1} \operatorname{Vec}(\tilde{V})
$$

Where:

$$
\tilde{\mathrm{V}}=\mathrm{X}_{0}+\widetilde{\mathrm{BEP}}=\left[\widetilde{\mathrm{v}}_{0}, \widetilde{\mathrm{V}}_{1}, \ldots, \widetilde{\mathrm{V}}_{\mathrm{m}-1}\right]
$$

$\mathrm{Vec}(\cdot)$ is a vector valued function (Brewer, 1978) of a matrix, say $\mathrm{A}(\mathrm{p} \times \mathrm{m})$ and it is defined by:

$$
\operatorname{Vec}(\mathrm{A})=\left[\begin{array}{c}
\mathrm{A}_{\cdot 1} \\
\mathrm{~A}_{\cdot 2} \\
\vdots \\
\mathrm{A}_{\cdot \mathrm{m}}
\end{array}\right]
$$


A pm vector, $I_{\mathrm{nm}}$ is the identity matrix of order $\mathrm{nm} \times \mathrm{nm}$ and $\mathrm{A} \otimes \mathrm{B}$ is the Kronecker product (Brewer, 1978) of 2 matrices $A(p \times m)$ and $B(q \times n)$ defined by:

$$
\mathrm{A} \otimes \mathrm{B}=\left[\begin{array}{cccc}
\mathrm{a}_{11} \mathrm{~B} & \mathrm{a}_{12} \mathrm{~B} & \cdots & \mathrm{a}_{1 \mathrm{~m}} \mathrm{~B} \\
\mathrm{a}_{21} \mathrm{~B} & \mathrm{a}_{22} \mathrm{~B} & \cdots & \mathrm{a}_{2 \mathrm{~m}} \mathrm{~B} \\
\vdots & \vdots & & \vdots \\
\mathrm{a}_{\mathrm{p1}} \mathrm{B} & \mathrm{a}_{\mathrm{p} 2} \mathrm{~B} & \cdots & \mathrm{a}_{\mathrm{pm}} \mathrm{B}
\end{array}\right]
$$

which is a pq $\times$ mn matrix. Though this method is straightforward, it is not attractive computationally as it involves inversion of a matrix of size qm or $\mathrm{nm}$ as Eq. 43 and 44 which becomes large as the value of $m$ increases. The accuracy of end result depends on $m$ value.

Recursive algorithm via BPFs: $\dot{e}(t)$ and $\dot{x}(t)$ were also expressed in terms of BPFs (Kawaji, 1983) to arrive at a recursive algorithm. Since, Eq. 36 and 39 were obtained only after integrating Eq. 8 and 13, there is no need to express $\dot{\mathrm{e}}(\mathrm{t})$ and $\dot{\mathrm{x}}(\mathrm{t})$ in terms of BPF to derive the recursive algorithm in the approach. Thus, the approach here is different from the one (Kawaji, 1983). Substituting matrix P of BPF into Eq. 36 and 39 and simplifying, we obtain:

$$
\begin{gathered}
e_{0}=\left(I_{m}-0.5 T F\right)^{-1} e\left(t_{0}\right) \\
e_{i}=\left(I_{m}-0.5 T F\right)^{-1}\left(I_{m}+0.5 T F\right) e_{i-1}
\end{gathered}
$$

for $\mathrm{i}=1,2,3, \ldots, \mathrm{m}-1$,

$$
\mathrm{x}_{0}=\left(\mathrm{I}_{\mathrm{n}}-0.5 \mathrm{~T} \tilde{\mathrm{A}}\right)^{-1}\left[\mathrm{x}\left(\mathrm{t}_{0}\right)+0.5 \mathrm{~TB} \mathrm{e}_{0}\right]
$$

$\mathrm{x}_{\mathrm{i}}=\left(\mathrm{I}_{\mathrm{n}}-0.5 \mathrm{~T} \tilde{\mathrm{A}}\right)^{-1}\left[\left(\mathrm{I}_{\mathrm{n}}+0.5 T \tilde{\mathrm{A}}\right) \mathrm{x}_{\mathrm{i}-1}+0.5 T \tilde{\mathrm{B}}\left(\mathrm{e}_{\mathrm{i}-1}+\mathrm{e}_{\mathrm{i}}\right)\right]$

for $\mathrm{i}=1,2,3, \ldots, \mathrm{m}-1$.

Recursive algorithm via SLPs: Substituting matrix $P$ of SLP into Eq. 36 and rearranging the terms, we have:

$$
\left[\begin{array}{cccccc}
\mathrm{W}_{00} & \mathrm{~W}_{01} & \bigcirc & \bigcirc & \cdots & \bigcirc \\
\mathrm{W}_{10} & \mathrm{~W}_{11} & \mathrm{~W}_{12} & \bigcirc & \cdots & \bigcirc \\
\bigcirc & \mathrm{W}_{21} & \mathrm{~W}_{22} & \mathrm{~W}_{23} & \cdots & \bigcirc \\
\vdots & \vdots & \vdots & \vdots & & \vdots \\
\bigcirc & \bigcirc & \bigcirc & \bigcirc & \cdots & \mathrm{W}_{\mathrm{m}-2, \mathrm{~m}-1} \\
\bigcirc & \bigcirc & \bigcirc & \bigcirc & \cdots & \mathrm{W}_{\mathrm{m}-1, \mathrm{~m}-1}
\end{array}\right]\left[\begin{array}{c}
\mathrm{s}_{0} \\
\mathrm{~s}_{1} \\
\mathrm{~s}_{2} \\
\vdots \\
\mathrm{s}_{\mathrm{m}-2} \\
\mathrm{~s}_{\mathrm{m}-1}
\end{array}\right]=\left[\begin{array}{c}
\mathrm{v}_{0} \\
\mathrm{v}_{1} \\
\mathrm{v}_{2} \\
\vdots \\
\mathrm{v}_{\mathrm{m}-2} \\
\mathrm{v}_{\mathrm{m}-1}
\end{array}\right]
$$

Where:

and

$$
\begin{aligned}
& W_{i j}= \begin{cases}\frac{2 I_{m}}{\left(t_{f}-t_{0}\right)}-F & \text { if } i=j=0 \\
\frac{F}{(2 i+3)} & \text { if } i=0,1,2, \ldots, m-2 \text { and } j=i+1 \\
\frac{-F}{(2 i-1)} & \text { if } i=1,2,3, \ldots, m-1 \text { and } j=i-1 \\
\frac{2 I_{m}}{\left(t_{f}-t_{0}\right)} & \text { if } i=j=1,2, \ldots, m-1 \\
0 & \text { otherwise }\end{cases} \\
& v_{i}=\left\{\begin{array}{c}
\frac{2 e\left(t_{0}\right)}{\left(t_{f}-t_{0}\right)} \text { if } i=0 \\
0 \quad \text { otherwise }
\end{array}\right.
\end{aligned}
$$

$$
\mathrm{s}_{\mathrm{i}}=\mathrm{e}_{\mathrm{i}} \text { for all } \mathrm{i}
$$

Similarly, substituting matrix P of SLP into Eq. 39 and rearranging the terms lead to Eq. 52 where:

$$
\begin{aligned}
& W_{i j}= \begin{cases}\frac{2 I_{n}}{\left(t_{f}-t_{0}\right)}-\tilde{A} \quad \text { if } i=j=0 \\
\frac{\tilde{A}}{(2 i+3)} \quad \text { if } i=0,1,2, \ldots, m-2 \text { and } j=i+1 \\
\frac{-\tilde{A}}{(2 i-1)} & \text { if } i=1,2,3, \ldots, m-1 \text { and } j=i-1 \\
\frac{2 I_{n}}{\left(t_{f}-t_{0}\right)} & \text { if } i=j=1,2, \ldots, m-1 \\
0 & \text { otherwise }\end{cases} \\
& V_{i}= \begin{cases}\frac{2 x\left(t_{0}\right)}{\left(t_{f}-t_{0}\right)}+\tilde{B}\left(e_{0}-\frac{1}{3} e_{1}\right) & \text { if } i=0 \\
\tilde{B}\left(\frac{e_{i-1}}{2_{i-1}} \frac{e_{i-1}}{2_{i+3}}\right. & \text { if } i=1,2, \ldots, m-2 \\
\tilde{B} \frac{e_{m-2}}{2_{m-3}} & \text { if } i=m-1\end{cases}
\end{aligned}
$$

and

$$
\mathrm{s}_{\mathrm{i}}=\mathrm{x}_{\mathrm{i}} \text { for all } \mathrm{i}
$$

Now, Eq. 52 with Eq. $53-55$ or Eq. $56-58$ can be solved recursively using the following recursive relations:

$$
\begin{gathered}
\mathrm{d}_{\mathrm{i}}= \begin{cases}\mathrm{M}_{\mathrm{ii}} \mathrm{v}_{\mathrm{i}} & \text { if } \mathrm{i}=\mathrm{m}-1 \\
\mathrm{M}_{\mathrm{ii}}\left(\mathrm{v}_{\mathrm{i}}-\mathrm{W}_{\mathrm{i}, \mathrm{i}+1} \mathrm{~d}_{\mathrm{i}+1}\right) & \text { if } \mathrm{i}=\mathrm{m}-2, \mathrm{~m}-3, \ldots, 1,0\end{cases} \\
\mathrm{R}_{\mathrm{i}, \mathrm{i}-1}=-\mathrm{M}_{\mathrm{ii}} \mathrm{W}_{\mathrm{i}, \mathrm{i}-1} \quad \text { for } \mathrm{i}=\mathrm{m}-1, \mathrm{~m}-2, \ldots, 2,1
\end{gathered}
$$




$$
\begin{gathered}
\mathrm{M}_{\mathrm{ii}}= \begin{cases}\mathrm{W}_{\mathrm{ii}}^{-1} & \text { if } \mathrm{i}=\mathrm{m}-1 \\
\left(\mathrm{~W}_{\mathrm{ii}}+\mathrm{W}_{\mathrm{i}, \mathrm{i}+1} \mathrm{R}_{\mathrm{i}+1, \mathrm{i}}\right)^{-1} & \text { if } \mathrm{i}=\mathrm{m}-2, \mathrm{~m}-3, \ldots, 1,0\end{cases} \\
\mathrm{s}_{0}=\mathrm{d}_{0} \\
\mathrm{~s}_{\mathrm{i}}=\mathrm{R}_{\mathrm{i}, \mathrm{i}-1} \mathrm{~s}_{\mathrm{i}-1}+\mathrm{d}_{\mathrm{i}} \quad \text { for } \mathrm{i}=1,2, \ldots, \mathrm{m}-1
\end{gathered}
$$

In Eq. 61, the size of the matrix to be inverted is kept to $\mathrm{q}$ or $\mathrm{n}$ instead of $\mathrm{qm}$ or $\mathrm{nm}$ as in the case of Kronecker product method. Moreover, the matrix in Eq. 52 is sparse which is fully exploited in deriving the recursive relations 59-63. This method is thus more attractive computationally.

Illustrative example: Consider the linear system (Kawaji, 1983; Chou and Horng, 1985a, b; Lee et al., 1986; Chang and Lee, 1986; Chung and Sun, 1987; Yang and Chen, 1988; Palanisamy and Raghunathan, 1989).

$$
\begin{gathered}
{\left[\begin{array}{l}
\dot{\mathrm{x}}_{1}(\mathrm{t}) \\
\dot{\mathrm{x}}_{2}(\mathrm{t})
\end{array}\right]=\left[\begin{array}{ll}
0 & 1 \\
1 & 0
\end{array}\right]\left[\begin{array}{l}
\mathrm{x}_{1}(\mathrm{t}) \\
\mathrm{x}_{2}(\mathrm{t})
\end{array}\right]+\left[\begin{array}{c}
0 \\
-1
\end{array}\right] \mathrm{u}(\mathrm{t}),\left[\begin{array}{l}
\mathrm{x}_{1}(0) \\
\mathrm{x}_{2}(0)
\end{array}\right]\left[\begin{array}{c}
-0.6 \\
0.35
\end{array}\right]} \\
\mathrm{y}(\mathrm{t})=\left[\begin{array}{ll}
1 & 0
\end{array}\right]\left[\mathrm{x}_{1}(\mathrm{t}) \mathrm{x}_{2}(\mathrm{t})\right]^{\mathrm{T}}
\end{gathered}
$$

Where, the optimal control law is taken to be:

$$
\mathrm{u}^{*}(\mathrm{t})=-\mathrm{K} \hat{\mathrm{x}}(\mathrm{t})=\left[\begin{array}{ll}
1.5 & 1
\end{array}\right]\left[\hat{\mathrm{x}}_{1}(\mathrm{t}) \quad \hat{\mathrm{x}}_{2}(\mathrm{t})\right]^{\mathrm{T}}
$$

due to incomplete measurement of the state and ${ }^{\hat{x}(t)}$ is obtained by the Luenberger observer:

$$
\begin{gathered}
\dot{z}(\mathrm{t})=-1.5 \mathrm{z}(\mathrm{t})-\mathrm{u}(\mathrm{t})-1.25 \mathrm{y}(\mathrm{t}), \mathrm{z}(0)=0.5 \\
{\left[\begin{array}{l}
\hat{\mathrm{x}}_{1}(\mathrm{t}) \\
\hat{\mathrm{x}}_{2}(\mathrm{t})
\end{array}\right]=\left[\begin{array}{c}
1 \\
1.5
\end{array}\right] \mathrm{y}(\mathrm{t})+\left[\begin{array}{l}
0 \\
1
\end{array}\right] \mathrm{z}(\mathrm{t})} \\
\mathrm{z}(\mathrm{t})=\left[\begin{array}{ll}
-1.5 & 1
\end{array}\right]\left[\begin{array}{ll}
\mathrm{x}_{1}(\mathrm{t}) & \mathrm{x}_{2}(\mathrm{t})
\end{array}\right]^{\mathrm{T}}+\mathrm{e}(\mathrm{t})
\end{gathered}
$$

which is designed as per the design procedure by Chang and Lee (1986) as follows: If we choose:

$$
\mathrm{L}_{1}=\left[\begin{array}{ll}
1 & 1.5
\end{array}\right]^{\mathrm{T}} \text { and } \mathrm{L}_{2}=\left[\begin{array}{ll}
0 & 1
\end{array}\right]^{\mathrm{T}}
$$

We can obtain $\Gamma$ from Eq. 9 as $\Gamma=\left[\begin{array}{ll}\gamma_{1} & \gamma_{2}\end{array}\right]=[-1.5$ 1]. Once $\Gamma$ is obtained, $\mathrm{G}$ can be computed from Eq. 5 as
$\mathrm{G}=-1$ and $\mathrm{F}$ and $\mathrm{H}$ can be computed from $\mathrm{Eq} .6$ as $\mathrm{F}=-1.5$ and $\mathrm{H}=-1.25$. Therefore, we have:

$$
\begin{gathered}
\mathrm{A}=\left[\begin{array}{ll}
0 & 1 \\
1 & 0
\end{array}\right], \mathrm{B}=\left[\begin{array}{c}
0 \\
-1
\end{array}\right], \mathrm{C}=\left[\begin{array}{cc}
1 & 0
\end{array}\right], \mathrm{K}=\left[\begin{array}{ll}
-1.5 & -1
\end{array}\right], \mathrm{F}=-1.5 \\
\mathrm{G}=-1, \mathrm{H}=-1.25, \mathrm{~L}_{1}=\left[\begin{array}{c}
1 \\
1.5
\end{array}\right], \mathrm{L}_{2}=\left[\begin{array}{l}
0 \\
1
\end{array}\right], \Gamma=\left[\begin{array}{ll}
-1.5 & 1
\end{array}\right] \\
\tilde{\mathrm{A}}=\mathrm{A}-\mathrm{BK}=\left[\begin{array}{cc}
0 & 1 \\
-0.5 & -1
\end{array}\right], \tilde{\mathrm{B}}=-\mathrm{BKL}_{2}=\left[\begin{array}{c}
0 \\
-1
\end{array}\right]
\end{gathered}
$$

We consider $m=4$ on each unit interval and compute $\mathrm{e}(\mathrm{t}), \mathrm{x}(\mathrm{t})$ and $\mathrm{u}^{*}(\mathrm{t})$ over $\mathrm{t}^{\prime} \in(0,5)$ using both the recursive algorithms. Figure 1 shows exact:

$$
e(t)=-0.75 e^{-1.5 t}
$$

and $\mathrm{e}(\mathrm{t})$ obtained via SLPs and BPFs. Figure 2 shows $\mathrm{x}_{1}(\mathrm{t})$ and $\mathrm{x}_{2}(\mathrm{t})$ obtained via SLPs and BPFs while Fig. 3 shows exact:

$$
u^{*}(t)=-0.75 e^{-1.5 t}+e^{-0.5 t}[1.9 \sin (0.5 t)-0.55 \cos (0.5 t)]
$$

and $\mathrm{u}^{*}(\mathrm{t})$ obtained via SLPs and BPFs. It can be observed from Fig. 1-3 that BPF approach always produces piecewise constant solution and SLP approach produces continuous solution. The results obtained by the proposed algorithms are in close agreement with the exact results. Moreover, the results obtained via the non recursive SLP approach by Chou and Horng (1985b) and the recursive BPF approach by Kawaji (1983) are also included for comparison sake. As can be seen, both the existing approaches (Kawaji, 1983; Chou and Horng, 1985b) and the proposed approaches have produced the same result. The proposed SLPs approach is faster

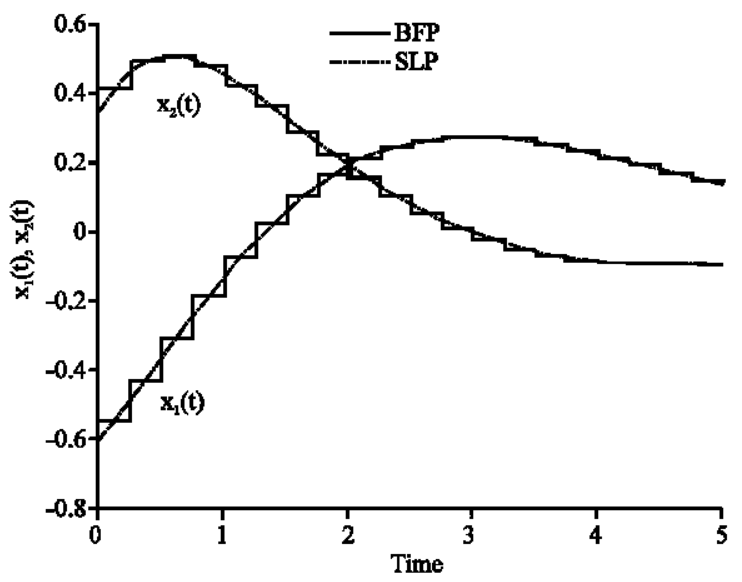

Fig. 1: Error 


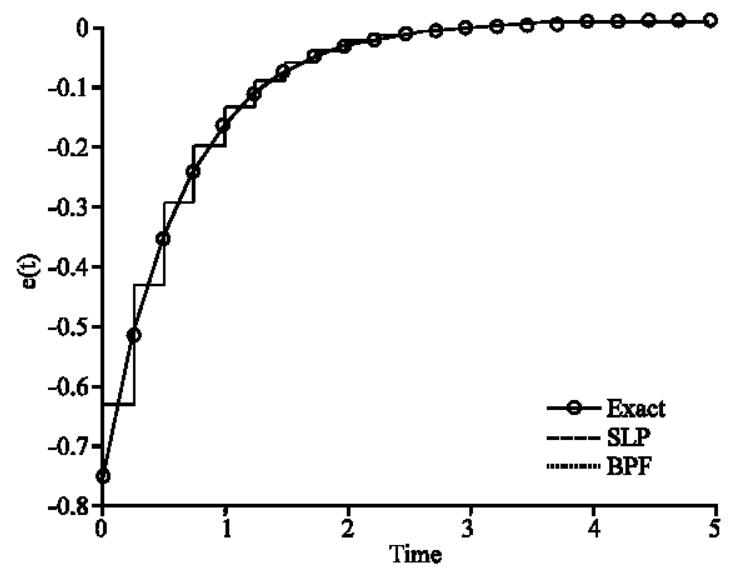

Fig. 2: State variables

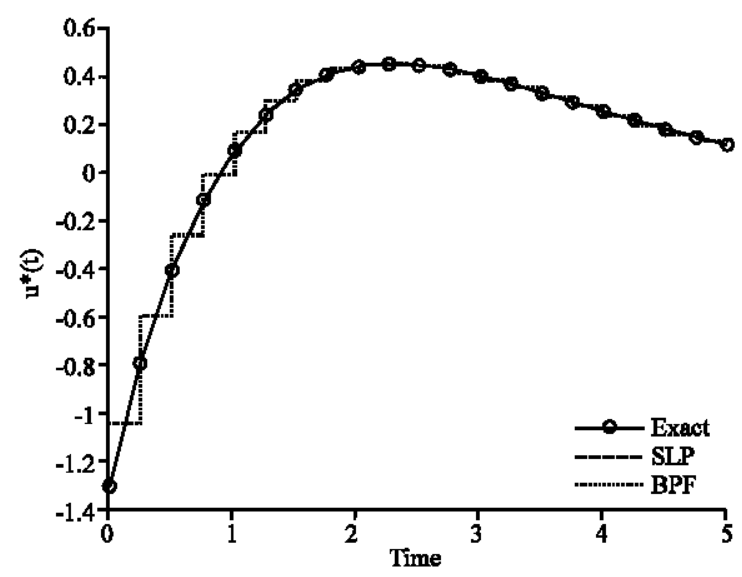

Fig. 3: Optimal control law

and less complex than the existing SLP approach as it is purely recursive in nature.

\section{CONCLUSION}

Based on BPFs and SLPs, two recursive algorithms are presented for analysis of linear optimal control systems incorporating observers. Computational superiority of these algorithms over the existing algorithms has been discussed. For a fixed value of $m$, the number of SLPs or BPFs, BPF algorithm is faster than SLP algorithm but its end result is piecewise constant; not smooth as in the case of SLP algorithm. So, one has a choice to choose a method (BPF or SLP) based on the requirement, i.e, speed of computation or accuracy of end result.

\section{REFERENCES}

Bongiorno, Jr. J.J. and D.C. Youla, 1968. On observers in multivariable control systems. Int. J. Control, 8: $221-243$
Brewer, J.W., 1978. Kronecker products and matrix calculus in system theory. IEEE Trans. Circuits Syst., 25: $772-781$.

Chang, Y.F. and T.T. Lee, 1986. General orthogonal polynomials analy-sis of linear optimal control systems incorporating observers. Int. J. Syst. Sci., 17: 1521-1535.

Chou, J.H. and I.R. Horng, 1985a. Shifted Legendre series analysis of linear optimal control systems incorporating observers. Int. J. Syst. Sci., 16: 863-867.

Chou, J.H. and I.R. Horng, 1985b. Shifted chebyshev series analysis of linear optimal control systems incorporating observers. Int. J. Control, 41: 129-134.

Chung, H.Y. and Y.Y. Sun, 1987. Fourier series analysis of linear opti-mal control systems incorporating observers. Int. J. Syst. Sci., 18: 213-220.

Datta, K.B. and B.M. Mohan, 1995. Orthogonal functions in systems and control. Adv. Ser. Electr. Comput. Eng., 9: 288-288.

De Melo, G.P. and T.S. Morais, 2007. Fault Detection Using State Observers with Unknown Input, Identified by Orthogonal Functions and PI Observers. In: Mechanics of Solids in Brazil, Alves, M. and H.S. da Costa-Mattos (Eds.). Brazilian Society of Mechanical Sciences and Engineering, Brazil, ISBN: 978-85-85769-30-7, pp: 357-373.

Fahroo, F. and I.M. Ross, 2001. Costate estimation by a Legendre pseudospectral method. J. Guid. Control Dyn., 24: 270-277.

Jiang, Z.H. and W. Schaufelberger, 1992. Block-Pulse Functions and Their Applications in Control Systems. Spinger-Verlag, Berlin.

Kawaji, S., 1983. Block-pulse series analysis of linear systems incorpo-rating observers. Int. J. Control, 37: 1113-1120.

Lee, T.T., S.C. Tsay and I.R. Horng, 1986. Shifted Jacobi series analysis of linear optimal control systems incorporating observers. J. Franklin Inst., 321: 289-298.

Luenberger, D.G., 1964. Observing the state of a linear system. IEEE Trans. Mil. Electr., 8: 74-80.

Palanisamy, K.R. and K.G. Raghunathan, 1989. Single-term Walsh series analysis of linear optimal control systems incorporating observers. Int. J. Syst. Sci., 20: 1149-1155.

Rao, G.P., 1983. Piecewise Constant Orthogonal Functions and their Applications to Systems and Control. Springer-Verlag, Berlin, USA.

Yang, C.Y. and C.K. Chen, 1988. Linear optimal control systems by reduced-order observers via orthogonal functions. Int. J. Syst. Sci., 19: 23-32. 